\title{
New insights in vitiligo treatments using bioactive compounds from Piper nigrum
}

\author{
BIANCA MIHĂILĂ $\breve{1}^{1}$, RODICA MIHAELA DINICA $\breve{~}^{2}$, ALIN LAURENȚIU TATU ${ }^{3}$ and OLIMPIA DUMITRIU BUZIA ${ }^{4}$ \\ ${ }^{1}$ SC Ecofarmacia Network SRL, 550253 Sibiu; ${ }^{2}$ Department of Chemistry, Faculty of Sciences and Environment, \\ 'Dunărea de Jos' University of Galați, 800201 Galați; ${ }^{3}$ Medical and Pharmaceutical Research Unit/Competitive, \\ Interdisciplinary Research Integrated Platform 'Dunărea de Jos', ReForm-UDJG; 'Research Centre in the Field of \\ Medical and Pharmaceutical Sciences', Faculty of Medicine, Department of Pharmacy/Pharmacology Sciences, \\ 'Dunărea de Jos' University of Galați; ${ }^{4}$ Medical and Pharmaceutical Research Unit, 'Research Centre in \\ the Field of Medical and Pharmaceutical Sciences', Faculty of Medicine, Department of Pharmacy/ \\ Pharmacology Sciences, ‘Dunărea de Jos’ University of Galaţi, Galați 800101, Romania
}

Received August 3, 2018; Accepted September 24, 2018

DOI: 10.3892/etm.2018.6977

\begin{abstract}
Although vitiligo is one of the most frequently occurring depigmentary disorder, its pathophysiology is still not fully clarified, resulting in the incapacity to find a targeted cure. Most of the treatment options available at the time have an anti-inflammatory or immunosuppressive effect, influencing the immune factor in vitiligo but without having a direct effect on melanocyte differentiation, migration or proliferation. This study shows that Piper nigrum (PN) extract and its main alkaloid, piperine, promote melanocyte proliferation in vivo, being consistent with previous study. A PN fruit extract and pure piperine were integrated in two different ointments and tested on human subjects affected by vitiligo. A number of 9 areas were treated: 3 using the extract, 3 using pure piperine, 1 using travoprost solution, and 2 using an association of travoprost (prostaglandin F $2 \alpha$ analogue) solution and our products. Pigmentation was achieved in all the treated areas. The extract caused faster and more remarkable results than the pure piperine. The association of the travoprost solution speed up the process and changed the pigmentation pattern, especially when associated with the PN extract. Our early studies suggest that PN extract may represent, in the future, a new treatment option for vitiligo, especially considering the mild side effects of the tested products and the reduced amount of time needed
\end{abstract}

Correspondence to: Professor Alin Laurentiu Tatu, Medical and Pharmaceutical Research Unit/Competitive, Interdisciplinary Research Integrated Platform 'Dunărea de Jos', ReForm-UDJG; 'Research Centre in the Field of Medical and Pharmaceutical Sciences', Faculty of Medicine, Department of Pharmacy/Pharmacology Sciences, 'Dunărea de Jos' University of Galați, 39 Al. I. Cuza Street, 800101 Galati, Romania

E-mail: dralin_tatu@yahoo.com

Key words: Piper nigrum, piperine, HPTLC, antioxidant activity for repigmentation. However, more studies are needed to validate this experimental data.

\section{Introduction}

Vitiligo is a skin disorder that causes the skin to lose its natural pigmentation (1). It can develop at any age and there is no difference in prevalence according to sex, skin type or race (2). The affected skin can lighten or turn completely white. Some people develop a few patches while others lose much more skin color. Usually there are no other signs or local symptoms. Vitiligo can also affect other parts of the body such us the hair, the eyes, the inside of the mouth or lips. Some people develop low self-esteem, social anxiety or serious depression $(1,3,4)$.

Usually vitiligo represents a standalone phenomenon but it can arise associated with other autoimmune conditions like thyroiditis, alopecia areata or lupus (5).

Two types of vitiligo are recognized: non-segmental (most common) and segmental. Non-segmental vitiligo is characterized by the development of depigmentation areas on both sides of the body, while segmental vitiligo is usually limited to one side of the body with typical distribution patterns in the face and trunk, which are useful for the differential diagnosis (6-9).

The therapeutic options in vitiligo include: topical potent or very potent corticosteroids, topical immunomodulators $(1,2,10)$; narrow-band UVB phototherapy $(11,12)$; oral corticosteroid mini-pulse therapy (2), surgical treatment (skin grafting); depigmentation with p-benzyloxyphenol, laser treatment, cryotherapy $(1,2)$, and long-term methotrexate (13). The side effects of those therapies may include: Skin atrophy, striae, telangiectasia, acne, scales, pustules, local endosymbiosis proliferation, contact allergy, immunosuppression, weight gain, sleep disturbances and others cited unpredictable effects $(2,10,14-26)$, so the treatment, as in other diseases, should be closely monitored (27-31).

The evolution of vitiligo can not be predicted: Some people see patches enlarge or new patches appear. On a rare occasion, the skin may regain its lost color without treatment $(9,32,33)$. 
Although the treatment options may seem numerous, they are rarely efficient in the long run. In most cases, vitiligo recurs over time. In addition, the uniqueness of each organism causes each person to respond differently and unpredictably to various treatments $(34,35)$.

Plant extracts have been used for the treatment of various diseases since ancient times, even in economic turn down decades (36-39). PN, one of the most widely used spices in the world, has also been used as medicine for centuries. In recent years the unique pharmacological actions of these plants have been explored. Among the phytochemicals in PN, the compound of interest in this study is piperine, the main alkaloid, responsible for the pungent taste (40). The phenolic amides from PN have also shown an antioxidant capacity superior to synthetic compounds. According to recent studies, PN can stimulate melanocyte proliferation and bring back color to depigmented skin (41), therefore this could be a potential treatment for vitiligo.

A crude extract of PN fruits containing piperine was shown to be more stimulatory that an equivalent concentration of the pure compound, suggesting the presence of other active components (42).

\section{Materials and methods}

The PN extract was obtained by Soxhlet extraction, using chloroform as solvent. The black peppercorns originary from India were purchased from the online store: www.pcfarm.ro. The powder resulted from grinding the dried fruits $(5 \mathrm{~g}$ of powder for each $25 \mathrm{ml}$ of solvent) were extracted for $24 \mathrm{~h}$, until the complete depletion of the plant product. The solvent was aftwerwards evaporated under vaccuum.

The CAMAG high performance thin layer cromatography (HPTLC) system was used for thin layer cromatography analysis, which helped to evaluate the variety of biological active compounds found in the extract and to identify the alkaloid of interest, piperine. The application of the samples on the silica gel plates (stationary phase) was done automatically, using the automatic sampler Linomat 5 . The plates were developed using the automatic developing chamber ADC2, in a mobile phase consisting in a mixture of hexane, ethyl acetate and glacial acetic acid (3:1:0.1) (43). Finally, using the TLC Visualizer 2, the plates were evaluated using UV light $(254 \mathrm{~nm})$.

Using a standard piperine solution, we identified the piperine in our extract (by use of the $R_{f}$ value) and approximately quantified its concentration.

The antioxidant activity of the extract was evaluated using the 2,2-diphenyl-1-picrylhydrazyl (DPPH) radical (44). This method consists in the inactivation of the DPPH radical by an antioxidant, which is measured spectrophotometrically, using a microplate reader. The samples used were prepared with the use of 3 main solutions: S1, standard piperine $[2 \mathrm{mg} / \mathrm{ml}$ dimethyl sulfoxide (DMSO)]; S2, PN extract (5 mg/ml DMSO); and $\mathrm{S} 3$, tyrosine $\left(0.25 \mathrm{mg} / \mathrm{ml} \mathrm{H}_{2} \mathrm{O}\right)$. The tested samples were: Q1 (0.1 $\mathrm{ml}$ of S1); Q2 (0.1 $\mathrm{ml}$ of S1 mixed with $0.8 \mathrm{ml}$ of S3); Q3 (0.1 ml of S2); Q4 (0.1 ml of S2 mixed with $0.8 \mathrm{ml}$ of S3); Q5 (0.1 ml of DMSO). We used ascorbic acid (Q6) as reference for the antioxidant activity. The influence of tyrosine on the antioxidant activity was also monitored (Q2, Q4) (Table I), since it is a precursor of melanin, which means including it in our ointments could be helpful.
Table I. RSC of piperine (Q1), extract (Q3), DMSO (Q5), ascorbic acid (Q6), and the influence of tyrosine association $(\mathrm{Q} 2, \mathrm{Q} 4)$.

\begin{tabular}{lcccccc}
\hline Item & Q1 & Q2 & Q3 & Q4 & Q5 & Q6 \\
\hline RSC (\%) & 7.14 & 7.87 & 21.24 & 26.19 & 1.46 & 78 \\
\hline
\end{tabular}

DMSO, dimethyl sulfoxide; RSC, radical scavenging capacity.

The ointment base we used consisted of cetyl alcohol, glycerin, sodium lauryl sulfate and water, to which we added our active compounds (PN extract and pure piperine) and preservatives (methyl parahydroxybenzoate and propyl parahydroxybenzoate). To ensure that our biologically active compounds reach the melanocytes, we also added an absorption promoter. For this purpose we chose DMSO, since according to a recent $e x$ vivo permeability study, it has the best skin penetration capacity and the least intense side effects (41).

The study was approved by the the Local Ethics Committee (Comisia de Etica Universitara, no. 3/30 of May 2018; Galați; Romania), and the in vivo testing took place only after obtaining the informed consent from the patients involved in the study.

We were able to skip the animal testing phase since this was already done in a previous study, with conclusive results (41). The testing was done in 3 human subjects, all female, aged between 40 and 70 years, comprising 18 vitiligo plaques, localized mostly on the limbs and neck. One of these subjects had segmental vitiligo while the other two had generalized (non-segmental) vitiligo. We tested the ointments alone and in association with a $40 \mu \mathrm{g} / \mathrm{ml}$ travoprost solution, since periocular pigmentation was observed during recent studies in patients treated with prostaglandin analogues for glaucoma (45-48). We also monitored the influence of the application technique on the effect by applying an occlusive dressing on some of the affected skin patches. The ointments were applied once a day, in the evening while the travoprost solution was applied once a day, in the morning, to avoid interactions at the application site. The testing spread over 12 weeks, evaluating the results every 3 weeks.

\section{Results}

The HPTLC analysis of our extract in the optimized solvent system is a qualitative and semi-quantitative chemical testing of PN fruits for the presence of phytoconstituents. The chromatogram revealed the presence of piperine alkaloid in our PN extract, in a concentration of $\sim 8 \%$. A wide range of compounds other than piperine can be observed in the extract (different spots in P1 and P2 samples; Fig. 1), when compared with the P3-P6 samples, which only contain pure piperine.

The antioxidant activity results are presented in Table I. We have analyzed the radical scavenging capacity of samples containing bioactive compounds (pure piperine, $\mathrm{PN}$ extract and mixtures of these with tyrosine) in various ratios to evaluate their synergism or antagonism. By comparing the values in Table I, it can be noticed that the addition of tyrosine to our samples increased the radical scavenging capacity (RSC) 


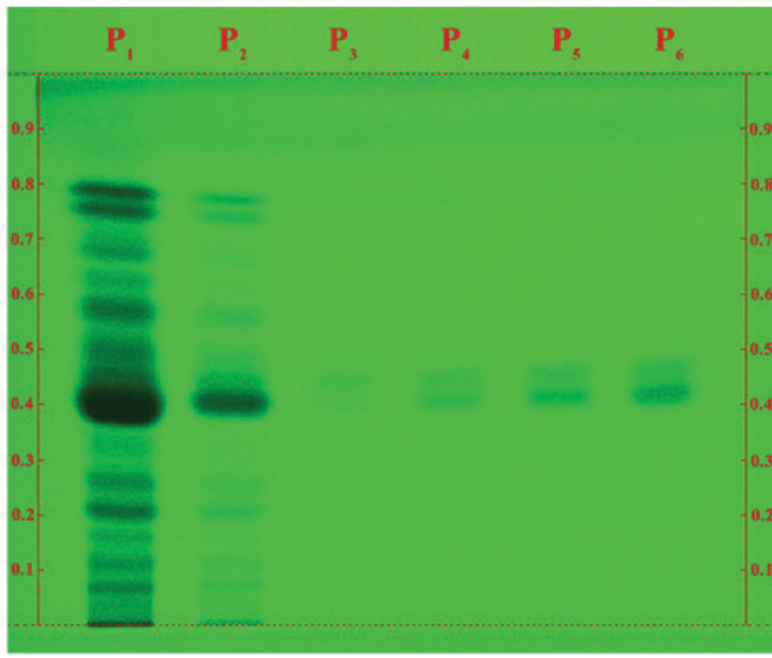

Figure 1. HPTLC chromatogram. P1, PN extract $(50 \mathrm{mg} / \mathrm{ml}) ; \mathrm{P} 2$, PN extract $(1 \mathrm{mg} / \mathrm{ml})$; P3-P6, pure piperine $(1 \mathrm{mg} / \mathrm{ml})$. HPTLC, high performance thin layer cromatography; PN, Piper nigrum.
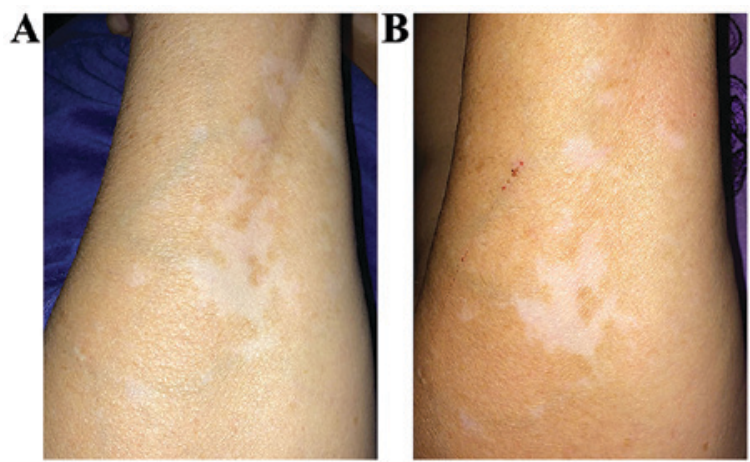

Figure 2. Pigmentation achieved after applying the PN extract ointment for 12 weeks. (A) initial moment; (B) final moment. PN, Piper nigrum.
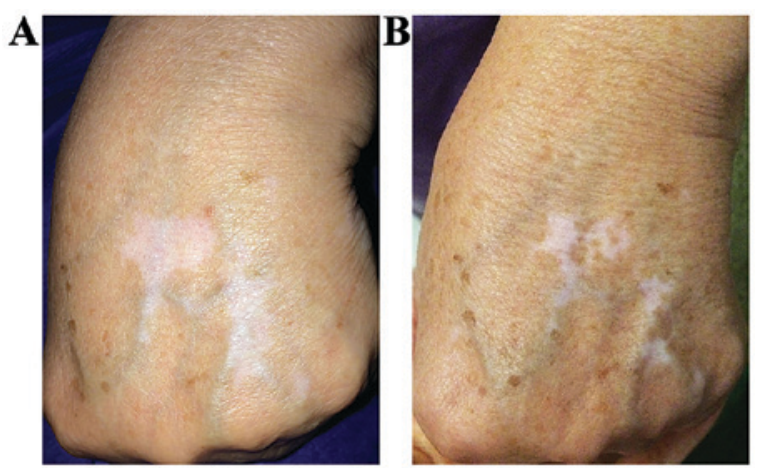

Figure 3. Pigmentation achieved after applying the PN extract ointment in association with the travoprost solution for 12 weeks. (A) initial moment; (B) final moment. PN, Piper nigrum.

value, both in the case of the PN extract and in the case of pure piperine alone. Q4, contaning PN extract and tyrosine has a greater RSC value than Q3, which contains just the PN extract. Similar to this, Q2, containing piperine and tyrosine has a greater RSC value than Q1, which only contains piperine. Dimethyl sulfoxide (DMSO) doesn't have an important influence on the antioxidant activity, since DMSO by itself (Q5)

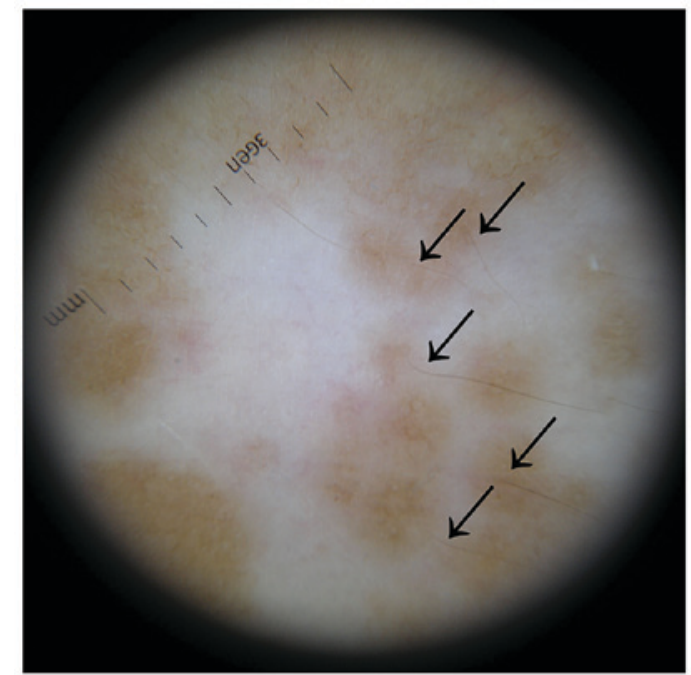

Figure 4. Dermatoscopic aspect of the pigmentation achieved after applying the PN extract ointment in association with the travoprost solution for 12 weeks. PN, Piper nigrum.
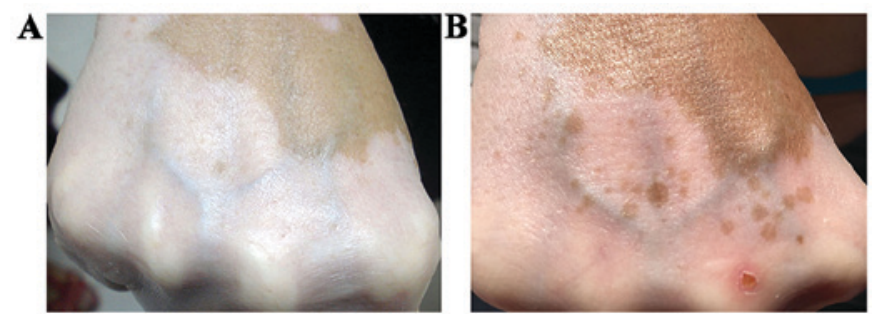

Figure 5. Pigmentation achieved after applying the PN extract ointment for 12 weeks in the non-segmental vitiligo case. (A) initial moment; (B) final moment. PN, Piper nigrum.

$\mathbf{A}$
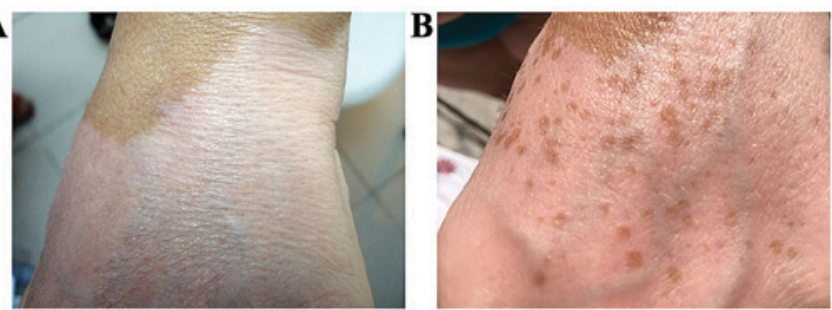

Figure 6. Pigmentation achieved after applying the pure piperine ointment for 12 weeks in the non-segmental vitiligo case. (A) initial moment; (B) final moment.

doesn't have a great RSC value. Taking all these into consideration, we can conclude that the tyrosine acts synergistically with the piperine and the PN extract.

Concerning the in vivo testing results, both of our ointments led to pigmentation of the affected skin areas. The pattern and the speed of pigmentation were different, depending on the substance and method of application. The most illustrative results are presented in figs. 2-6.

\section{Discussion}

Our study confirms the presence of piperine in PN and its capacity to stimulate pigmentation in the skin. The HPTLC 
results highlight the large variety of compounds that can be found in PN, which is an important fact considering they could all have therapeutic properties. Also, two $\mathrm{R}_{\mathrm{f}}$ values can be observed in the chromatograms, suggesting the presence of two isomers in the pure piperine solution, both also present in our extract.

The antioxidant capacity is relevant to our study because of the implications of oxidative stress in the physiopathology of vitiligo. The RSC of the PN extract was approximately three times bigger than the one of pure piperine, due to the other bioactive compounds from the extract. The association of tyrosine seems to be beneficial, increasing the antioxidant activity by $10 \%$ (when associated with piperine: Q2) to $20 \%$ (when associated with the extract: Q4) (Table I). Unfortunately, we were not able to include the tyrosine in our ointments because of the $\mathrm{pH}$ incompatibility between tyrosine $(\mathrm{pH}$ 5.0) on the one hand, and our extract $(\mathrm{pH} 9.0)$ and piperine $(\mathrm{pH} 9.5)$ on the other hand.

The in vivo testing results were satisfactory, regarding both ointments. The ointment containing the PN extract led to the fastest results, the pigmentation being visible to the naked eye after only 3 weeks of application. This suggests the presence of other biologically active compounds playing an important role in the pigmentation process, a fact highlighted by the HPTLC results and consistent with the findings of previous studies (42).

As to the pigmentation pattern, a difference between the active compounds was noted: The PN extract led to pigmentation islands while the piperine alone led to a diffuse pigmentation.

The association of the travoprost solution was beneficial in both cases. Not only did it speed up the process but it also changed the pigmentation pattern, especially when associated with the extract. The travoprost solution alone caused a diffuse pigmentation at first, visible after only 3 weeks, changing the pattern to pigmentation islands after 9 weeks. When associated with the extract ointment, both patterns of pigmentation were observed.

Applying the ointments under an occlusive dressing did not bring as much benefit as we expected. It led to fast pigmentation in the first 3 weeks but did not keep up the pace for the rest of the testing period.

By analyzing the affected areas with a dermatoscope, we were able to see that the pigmentation islands appeared around the pigmented hairs (Fig. 4). This is consistent with the scientific literature affirming that re-pigmentation tends to occur mainly in those areas of skin where there are still pigmented hairs, since this suggests the presence of melanin reservoirs (49).

Regarding the subject with non-segmental vitiligo, the results were almost the opposite. The difference between the two ointments was not as noticeable and, moreover, the piperine alone led to slightly better results than the extract. Also, they both produced pigmentation islands, thus following the same pattern. However, this could be the consequence of the patches of affected skin being larger than the ones of the segmental vitiligo subject.

The side effects of our ointments were easily tolerated by our subjects. They described a slight burning sensation at the first applications, especially when applying the extract ointment under an occlusive dressing. Yet, one of the subjects withdrew from the study because of the intense burning sensation and the local redness and irritation. This might be caused by the sensitive and hyper-reactive skin type of the subject.

The present study has limitations due to the small number of patients and lesions and the absence of controls. In the future, larger batches of patients should be included. This was just the start point for further studies and observations on this novel, simple and cheap possible treatment for vitiligo; these first observations regarding the synthesis, pharmacologic content and clinical effects have to be reported. We believe that our study contains promising results that should be investigated further, especially taking into consideration the current context, in which identifying plant compounds that are active in diseases such as vitiligo is of great importance.

Although the results may not be permanent, PN and piperine could represent a less aggressive treatment alternative for vitiligo than the ones that are currently used. However, further studies are necessary to establish certain details such as how long does the pigmentation last, what happens once the application is interrupted or in what way could the skin type or color influence the results.

\section{Acknowledgements}

Not applicable.

\section{Funding}

No funding was received.

\section{Availability of data and materials}

All data generated or analyzed during this study are included in this published article.

\section{Authors' contributions}

RMD prepared and analyzed the extract. ODB performed the ointment formulation. BM was involved in all the stages of the study, prepared the ointments and was a major contributor in writing the manuscript. ALT examined the test subjects and evaluated the in vivo effects. All authors contributed to the conception and design of the study, as well as revising it. All authors read and approved the final manuscript to be published and agreed to be accountable for all aspects of the work in ensuring that questions related to the accuracy or integrity of any part of the work are appropriately investigated and resolved.

\section{Ethics approval and consent to participate}

The study was approved by the Local Ethics Commission of Comisia de Etica Universitara (CEU no. 3/30 of May 2018; Galați, Romania), and written informed consent for participation in the study was obtained from all patients.

\section{Patient consent for publication}

Written informed consent for the publication of the images was provided by all participants. 


\section{Competing interests}

The authors declare that they have no competing interests.

\section{References}

1. Gawkrodger DJ, Ormerod AD, Shaw L, Mauri-Sole I, Whitton ME, Watts MJ, Anstey AV, Ingham J and Young K; Therapy Guidelines and Audit Subcommittee, British Association of Dermatologists; Clinical Standards Department, Royal College of Physicians of London; Cochrane Skin Group; Vitiligo Society: Guideline for the diagnosis and management of vitiligo. Br J Dermatol 159: 1051-1076, 2008.

2. Speeckaert R and van Geel N: Vitiligo: An update on pathophysiology and treatment options. Am J Clin Dermatol 18: 733-744, 2017.

3. Nicolaidou E, Antoniou C, Stratigos A and Katsambas AD: Narrowband ultraviolet B phototherapy and 308-nm excimer laser in the treatment of vitiligo: A review. J Am Acad Dermatol 60: 470-477, 2009.

4. Whitton ME, Ashcroft DM and González U: Therapeutic interventions for vitiligo. J Am Acad Dermatol 59: 713-717, 2008

5. Tatu AL and Ionescu MA: Multiple autoimmune syndrome type III-thyroiditis, vitiligo and alopecia areata. Acta Endo Buc 13: 124-125, 2017.

6. Taïeb A and Picardo M: Clinical practice. Vitiligo. N Engl J Med 360: 160-169, 2009.

7. Kim DY, Oh SH and Hann SK: Classification of segmental vitiligo on the face: Clues for prognosis. Br J Dermatol 164: 1004-1009, 2011.

8. van Geel N, Bosma S, Boone B and Speeckaert R: Classification of segmental vitiligo on the trunk. Br J Dermatol 170: 322-327, 2014.

9. Mazereeuw-Hautier J, Bezio S, Mahe E, Bodemer C, Eschard C, Viseux V, Labreze C, Plantin P, Barbarot S, Vabres P, et al; Groupe de Recherche Clinique en Dermatologie Pédiatrique (GRCDP): Segmental and nonsegmental childhood vitiligo has distinct clinical characteristics: A prospective observational study. J Am Acad Dermatol 62: 945-949, 2010.

10. Ho N, Pope E, Weinstein M, Greenberg S, Webster C and Krafchik BR: A double-blind, randomized, placebo-controlled trial of topical tacrolimus $0 \cdot 1 \%$ vs. clobetasol propionate $0.05 \%$ in childhood vitiligo. Br J Dermatol 165: 626-632, 2011.

11. Anbar TS, Westerhof W, Abdel-Rahman AT and El-Khayyat MA Evaluation of the effects of NB-UVB in both segmental and nonsegmental vitiligo affecting different body sites. Photodermato Photoimmunol Photomed 22: 157-163, 2006.

12. Cavalié M, Ezzedine K, Fontas E, Montaudié H, Castela E, Bahadoran P, Taïeb A, Lacour JP and Passeron T: Maintenance therapy of adult vitiligo with $0.1 \%$ tacrolimus ointment: A randomized, double blind, placebo-controlled study. J Invest Dermatol 135: 970-974, 2015.

13. Garza-Mayers AC and Kroshinsky D: Low-dose methotrexate for vitiligo. J Drugs Dermatol 16: 705-706, 2017.

14. Radakovic-Fijan S, Fürnsinn-Friedl AM, Hönigsmann H and Tanew A: Oral dexamethasone pulse treatment for vitiligo. J Am Acad Dermatol 44: 814-817, 2001

15. Tatu AL, Ionescu MA, Clatici VG and Cristea VC: Bacillus cereus strain isolated from Demodex folliculorum in patients with topical steroid-induced rosaceiform facial dermatitis. An Bras Dermatol 91: 676-678, 2016.

16. Tatu AL: Topical steroid induced facial rosaceiform dermatitis Acta Endo Buc 12: 232-233, 2016.

17. Kubiak K, Sielawa H, Chen W and Dzika E: Endosymbiosis and its significance in dermatology. J Eur Acad Dermatol Venereol 32: 347-354, 2018

18. Tatu AL, Ionescu MA and Nwabudike LC: Contact allergy to topical mometasone furoate confirmed by rechallenge and patch test. Am J Ther 25: e497-e498, 2018.

19. Tatu AL, Clatici V and Cristea VC: Isolation of Bacillus simplex strain from Demodex folliculorum and observations about Demodicosis spinulosa. Clin Exp Dermatol 41: 818-820, 2016.

20. Tatu AL, Ionescu MA and Cristea VC: Demodex folliculorum associated Bacillus pumilus in lesional areas in rosacea. Indian J Dermatol Venereol Leprol 83: 610-611, 2017.
21. Gambichler T, Rüddel I, Hessam S, Bechara FG, Stockfleth E and Schmitz L: Altered epigenetic pathways and cell cycle dysregulation in healthy appearing skin of patients with koebnerized squamous cell carcinomas following skin surgery. J Eur Acad Dermatol Venereol: Feb 25, 2018 (Epub ahead of print). doi: $10.1111 /$ jdv.14887.

22. Tatu AL and Nwabudike LC: Rosacea-like demodicosis (but not primary demodicosis) and papulo pustular rosacea may be two phenotypes of the same disease - a microbioma, therapeutic and diagnostic tools perspective. J Eur Acad Dermatol Venereol: Jun 29, 2018 (Epub ahead of print). doi: 10.1111/jdv.15166.

23. Tatu AL: Nasal spinulosis. J Cutan Med Surg 21: 339, 2017.

24. Tatu AL and Cristea VC: Pityriasis folliculorum of the back thoracic area: Pityrosporum, keratin plugs, or demodex involved? J Cutan Med Surg 21: 441, 2017.

25. Tatu AL and Cristea VC: Unilateral blepharitis with fine follicular scaling. J Cutan Med Surg 21: 442, 2017.

26. Tatu AL and Nwabudike LC: Reply to Happle R. et al. Koebner's sheep in Wolf's clothing: does the isotopic response exists as a distinct phenomenon? J Eur Acad Dermatol Venereol: Feb 28 , 2018 (Epub ahead of print). doi: 10.1111/jdv.14900.

27. Negrei C, Căruntu C and Ginghină O, Burcea-Dragomiroiu GT, Toderescu CD and Boda D: Qualitative and quantitative determination of methotrexate polyglutamates in erythrocytes by high performance liquid chromatography. Rev Chim 66: 607-610, 2015.

28. Negrei C, Ginghină O and Căruntu C, Burcea-Dragomiroiu GT, Jinescu G and Boda D: Investigation relevance of methotrexate polyglutamates in biological systems by high performance liquid chromatography. Rev Chim 66: 766-768, 2015.

29. Batani A, Brănișteanu DE, Ilie MA, Boda D, Ianosi S, Ianosi G and Caruntu C: Assessment of dermal papillary and microvascular parameters in psoriasis vulgaris using in vivo reflectance confocal microscopy. Exp Ther Med 15: 1241-1246, 2018.

30. Ion R and Boda D: Porphyrin-based supramolecular nanotubes generated by aggregation processes. Rev Chim 59: 205-207, 2008.

31. Boda D and Ion RM: Synthesis, spectral and photodynamic properties of lithium phthalocyanine. Rev De Chim 65: 1271-1274, 2014

32. Wolff K, Goldsmith LA, Katz SI, Gilchrest BA, Paller AS and Leffell DJ: Fitzpatrick's Dermatology in General Medicine. 7th edition. McGraw Hill Medical, USA, pp616-621, 2008.

33. Ortonne JP: Vitiligo and other disorders of hypopigmentation. In: Dermatology. Bolognia JL, Jorizzo JL and Rapini RP (eds). 2nd edition. Mosby Elsevier, Simi Valley, CA, USA, pp913-920, 2008.

34. Tatu AL and Nwabudike LC: Metoprolol-associated onset of psoriatic arthropathy. Am J Ther 24: e370-e371, 2017.

35. Tatu AL and Nwabudike LC: Bullous reactions associated with COX-2 inhibitors. Am J Ther 24: e477-e480, 2017.

36. Buzia OD, Fasie V, Mardare N, Diaconu C, Gurau G and Tatu AL: Formulation, preparation, physico-chimical analysis, microbiological peculiarities and therapeutic challenges of extractive solution of Kombucha. Rev Chim Buchar 69: 720-724, 2018.

37. Zălaru C, Crişan C, Călinescu I, Moldovan Z, Ţârcomnicu I, Litescu S, Tatia R, Moldovan L, Boda D and Iovu M: Polyphenols in Coreopsis tinctoria Nutt. fruits and the plant extracts antioxidant capacity evaluation. Open Chem 12: 858-867, 2014.

38. Ionescu C, Târcomnicu I, Ionescu MA, Nicolescu TO, Boda D and Nicolescu F: Identification and characterization of the methanolic extract of hellebrigenin 3-acetate from hellebori rhizomes. Mass spectrometry. Rev Chim 1: 972-975, 2014.

39. Raţiu MP, Purcărea I, Popa F, Purcărea VL, Purcărea TV, Lupuleasa D and Boda D: Escaping the economic turn down through performing employees, creative leaders and growth driver capabilities in the Romanian pharmaceutical industry. Farmacia 59: 119-130, 2011

40. Meghwal M and Goswami TK: Chemical composition, nutritional, medicinal and functional properties of black pepper: A review. Open Access Sci Rep 1: 172, 2012.

41. Faas L, Venkatasamy R, Hider RC, Young AR and Soumyanath A: In vivo evaluation of piperine and synthetic analogues as potential treatments for vitiligo using a sparsely pigmented mouse model. Br J Dermatol 158: 941-950, 2008.

42. Lin Z, Liao Y, Venkatasamy R, Hider RC and Soumyanath A: Amides from Piper nigrum L. with dissimilar effects on melanocyte proliferation in-vitro. J Pharm Pharmacol 59: 529-536, 2007.

43. Hamrapurkar PD: Kavita Jadhav and Sandip Zine: Quantitative estimation of piperine in Piper nigrum and Piper longum using high performance thin layer chromatography. J Appl Pharm Sci 1: 117-120, 2011 
44. Bozin B, Mimica-Dukic N, Samojlik I, Goran A and Igic R: Phenolics as antioxidants in garlic (Allium sativum L., Alliaceae). Food Chem 111: 925-929, 2008.

45. Choi YM, Diehl J and Levins PC: Promising alternative clinical uses of prostaglandin F2 $\alpha$ analogs: Beyond the eyelashes. J Am Acad Dermatol 72: 712-716, 2015.

46. Kapur R, Osmanovic S, Toyran S and Edward DP: Bimatoprostinduced periocular skin hyperpigmentation: Histopathological study. Arch Ophthalmol 123: 1541-1546, 2005.

47. Feletti F, Vincenzi C, Pazzaglia M and Tosti A: Periocular pigmentation associated with use of travoprost for the treatment of alopecia areata of the eyelashes. J Eur Acad Dermatol Venereol 21: 421-423, 2007.
48. Anbar TS, El-Ammawi TS, Abdel-Rahman AT and Hanna MR: The effect of latanoprost on vitiligo: a preliminary comparative study. Int J Dermatol 54: 587-593, 2015.

49. Menon SM, Sharma YK, Bansal P and Ghadgepatil SS: Restoration of pigmentation by follicular unit extraction transplant in three cases of focal vitiligo recalcitrant to therapy including with previous nonculture melanocyte-keratinocyte transplant. Int J Trichology 8: 87-88, 2016.

(i)@ $\Theta$ This work is licensed under a Creative Commons cc) Attribution-NonCommercial-NoDerivatives 4.0 International (CC BY-NC-ND 4.0) License. 